\title{
Maternal nutritional adequacy and gestational weight gain and their associations with birth outcomes among Vietnamese women
}

\author{
Nga Thuy Tran', Lam Thi Nguyen², Yatin Berde ${ }^{3}$, Yen Ling Low ${ }^{4}$, Siew Ling Tey ${ }^{4}$ and Dieu Thi Thu Huynh ${ }^{4 *}$
}

\begin{abstract}
Background: During pregnancy, a mother's nutritional needs increase to meet the added nutrient demands for fetal growth and development. An enhanced understanding of adequate nutrition and sufficient weight gain during pregnancy can guide development of policies and strategies for maternal nutrition care, actions that will ultimately promote better pregnancy outcomes. In a sample of pregnant women in Vietnam, this study characterized maternal nutrition status and gestational weight gain at a mid-pregnancy baseline, then examined the association of these variables with specific birth outcomes.
\end{abstract}

Methods: The study used baseline data from a randomized, controlled trial that compared pregnant Vietnamese women who received a nutritional intervention group with those who received only standard dietary counseling (control group). At baseline (26-29 weeks gestation), mothers' dietary reports were collected, and intake of 10 macroand micronutrients was estimated; data for baseline gestational weight gain was collected for all pregnant women enrolled into the study $(n=228)$. This analysis also used weights, lengths, and head circumferences at birth for infants of mothers in the control group.

Results: At baseline, 95\% of the pregnant women had concurrent inadequacies for more than five nutrients, and nearly half had concurrent inadequacies for more than ten nutrients. Almost two-thirds of the pregnant women did not meet recommendations for gestational weight gain. We found a significant, inverse association between the number of nutrient inadequacies and gestational weight gain (overall $p \leq 0.045$ ). After adjusting for potential confounders, gestational weight gain was positively associated with birth weight, length at birth, birth weight-for-age $z$-score and length-for-age $z$-score (all $p \leq 0.006$ ).

Conclusions: Our findings raise concern over the high proportion of pregnant women in Vietnam who have multiple concurrent nutrient inadequacies and who fall short of meeting recommended gestational weight gain standards. To ensure better birth outcomes in this population, policies and strategies to improve the status of maternal nutrition are greatly needed.

Trial registration: The trial was retrospectively registered at clinicaltrials.gov on December 20, 2013, registration identifier: NCT02016586.

Keywords: Maternal nutritional status, Gestational weight gain, Nutritional adequacy, Birth outcomes

\footnotetext{
* Correspondence: dieu.huynh@abbott.com

${ }^{4}$ Abbott Nutrition Research and Development Asia-Pacific Center, 20 Biopolis

Way, Unit 09-01/02 Centros Building, Singapore 138668, Singapore

Full list of author information is available at the end of the article
}

(c) The Author(s). 2019 Open Access This article is distributed under the terms of the Creative Commons Attribution 4.0 International License (http://creativecommons.org/licenses/by/4.0/), which permits unrestricted use, distribution, and reproduction in any medium, provided you give appropriate credit to the original author(s) and the source, provide a link to the Creative Commons license, and indicate if changes were made. The Creative Commons Public Domain Dedication waiver (http://creativecommons.org/publicdomain/zero/1.0/) applies to the data made available in this article, unless otherwise stated. 


\section{Background}

Pregnancy is a crucial time for women to be wellnourished. The added nutrient demands of fetal growth and development must be met in order to ensure optimal birth and growth outcomes. A suboptimal maternal diet and inadequate gestational weight gain during pregnancy increase risk for adverse health outcomes for both mother and child [1-5].

Inadequate macronutrient intake is common among pregnant women in some Asian countries, and certain micronutrient deficiencies are also frequent. Nutrients of particular concern include iron, zinc, folate, vitamin A, vitamin $\mathrm{D}$, iodine, and calcium, which play significant roles in maternal health and fetal development [6-11]. Nutrient inadequacies during pregnancy can impair fetal growth, which can in turn increase risk for low weight at birth or small-for-gestational-age and preterm deliveries [12-16]. Inadequate nutrient intakes during this time may also lead to reprogramming within fetal tissues, which is associated with increased risk for noncommunicable chronic diseases in adulthood [5, 17-20]. Thus, for pregnant women who have difficulty achieving recommended nutrient intake through usual diet alone, it is strategic to intervene with supplements containing protein, energy, and other nutrients.

Suboptimal weight gain during pregnancy has also been reported as highly prevalent in studies of other Asian populations [21-24]. Results of such studies found significant associations between inadequate gestational weight gain and poor pregnancy outcomes [21-30]. Findings from a recent meta-analysis showed that inadequate gestational weight gain was associated with increased risk of preterm birth by $70 \%$ (95\% CI: 32 to 120\%) and increased risk of delivering a small-for-gestational-age infant by 53\% (95\% CI: 44 to $64 \%$ ) [26]. Further, such small infants may experience nutritional shortfalls owing to failure to initiate breastfeeding. Dietary inadequacy in infants can lead to impaired growth and cognitive development in childhood, and even to adverse metabolic consequences in adulthood [31-33]. Strategies aimed to promote appropriate weight gain during pregnancy have the potential to improve birth outcomes, and these strategies may also generate significant intergenerational benefits [32, 34-37].

To our knowledge, data are limited on maternal nutritional status during pregnancy and its association with birth outcomes in developing countries such as Vietnam. The objectives of the present study were to (1) report adequacy of maternal nutrition and gestational weight gain at baseline (26-29 weeks gestation) among all the pregnant women enrolled in this Vietnamese study, and to (2) examine the association of these factors with specific birth outcomes (infant weight, length, and head circumference or the related $\mathrm{z}$-scores for each) for infant's whose mothers were in the standard care (control) group.
Better understanding of associations between markers of maternal nutrition status and infant birth outcomes can guide development of appropriate prenatal nutrition policies, guidelines, and practices for better outcomes to pregnancy.

\section{Methods \\ Study design and population}

The present study analysed a subset of data collected in a prior study, which has been described previously [38]. Briefly, the full study was a prospective, randomized, openlabel, parallel-group, multi-center design. It was conducted in 20 community medical stations and district hospitals across four Northern provinces in Vietnam between October 2013 and April 2015. Study eligibility requirements for women were: healthy and pregnant, 20-35 years of age, first-time mothers with singleton pregnancies, at 26 to 29 weeks of gestation, and with pre-pregnancy body mass index $(\mathrm{BMI})<25.0 \mathrm{~kg} / \mathrm{m}^{2}$ (not overweight or obese).

For the original study, a total of 228 singleton mothers took part in a randomized controlled trial with two groups: Intervention - daily maternal nutritional supplementation containing macronutrients and a variety of micronutrients starting from baseline (26-29 weeks gestation) to 12 weeks postpartum plus a breastfeeding support program (intervention group) or (B) Control standard-of-care treatment, including iron and folic acid supplementation until delivery. For the present analysis, we included data on mothers' socio-demographic characteristics, nutritional adequacy, and gestational weight gain at baseline; we included data on infants' weights, lengths, and head circumferences at birth.

\section{Maternal characteristics and nutritional status}

Descriptive maternal characteristics were collected at baseline. Socio-demographics included questions on maternal age, and highest education qualification. Economic status was determined by constructing a wealth index based on asset ownership from an inventory of household assets [39].

Maternal nutritional status was assessed using anthropometric measurements and dietary intake. Selfreported pre-pregnancy weight or the earliest measured weight in the first trimester from hospital record was recorded. In addition, measured height, weight, and midupper arm circumference were collected at baseline. Standing height and weight were measured using a height and weight scale (Horse Head Brand TZ-120). Body mass index $\left(\mathrm{kg} / \mathrm{m}^{2}\right)$ was calculated by dividing weight $(\mathrm{kg})$ by height squared $\left(\mathrm{m}^{2}\right)$ and maternal underweight was defined as having a pre-pregnancy $\mathrm{BMI}<$ $18.5 \mathrm{~kg} / \mathrm{m}^{2}$ [40, 41]. Gestational weight gain during the first and second trimesters was calculated by subtracting pre-pregnancy weight from weight at 26 to 29 weeks and this was compared with the Institute of Medicine (IOM) 
recommended gestational weight gain to determine whether the pregnant women met the IOM recommendation based on their pre-pregnant BMI and the recommended weight gain at the particular trimester of their pregnancy [40]. Mid-upper arm circumference was measured from the upper left arm using a measuring tape and a cut-off of $<23.0 \mathrm{~cm}$ was considered suboptimal nutritional status [42]. Dietary intake was collected at baseline by trained research staff using a standardized 24-h recall method. Nutrient adequacy was defined as $77 \%$ of the 2016 recommended daily allowance (RDA) for Vietnam [43] as the cutoff value [44]. We chose this criterion and cutoff because the estimated average requirement (EAR) is available for some (but not all) nutrients in Vietnam.

\section{Birth outcomes}

Medical records were used to obtain information on delivery mode (vaginal or caesarean), as well as gestational age, infant's weight, length, and head circumference at birth. The weight and length of the infant were obtained using a Seca 232 measuring rod. The head circumference was determined by measuring tape. World Health Organization (WHO) Child Growth Standards were used to calculate the sex-age-specific $z$-scores for infant's weight, length, and head circumference [45]. Small-forgestational-age was defined as birth weight and/or birth length at least two standard deviations below the mean level for sex and gestational age [46].

\section{Statistical analysis}

Maternal characteristics and nutrient inadequacies of all participants $(n=226)$ were presented as arithmetic means and standard deviations for continuous variables; categorical data were presented as numbers and percentages.

A simple linear regression model was used to examine the association at baseline of each single nutrient and as concurrent nutrient inadequacies (grouped as $\leq 5,6-10$, and 11-15 inadequate nutrients) with gestational weight gain at 26 to 29 weeks in all participants $(n=226)$.

Multiple regression analyses were used to assess the association of various factors with birth outcomes (birth weight, length, head circumference, birth weight-for-age $z$-score, length-for-age $z$-score, and head circumferencefor-age $z$-score) in the control group only $(n=113)$. These factors (at baseline) included mother's age, educational level, economic status, gestational weight gain, nutrient inadequacies, energy intake, energy-adjusted macronutrient intake, and infant's gestational age at birth and sex.

The modelling process for multiple regression analyses was started with the bivariate analysis in which the association between a single factor and the birth outcome was examined. Factors with $p$-values $<0.2$ from preliminary models were included in the final model. Mother's age, gestational age of infant at birth, and infant's sex are known to influence birth outcomes, so these three variables were also included in the final multiple regression models. The adjusted estimates and the $95 \%$ confidence interval derived from the final models were reported. All variables that were included in the models were defined a priori, and collinearity was examined in all the models. Data from the original intervention group were not included in any of the analyses for birth outcomes, as those mothers received maternal nutritional supplementation and breastfeeding support during the study, which significantly improved birth outcomes [38].

Birth outcomes were compared between study groups using analysis of covariance (ANCOVA) to control for confounding factors, including treatment group, mother's age, mother's nutritional status at baseline, socioeconomic status, gestational age and infant's gender.

SAS version 9.3 (SAS Institute, Cary, NC, USA) was used for all statistical analyses. All statistical tests were two-sided and $p<0.05$ was considered statistically significant.

\section{Results}

\section{Maternal characteristics}

Of the 228 mothers enrolled into the study, 226 women were successfully randomized to either the intervention group $(n=113)$ or the control group $(n=113)$ and were included in an intention-to-treat analysis [38]. As shown in Table 1 , the mean $( \pm \mathrm{SD})$ age of the mothers was 24.0 $( \pm 2.9)$ years old, and the mean $(\mathrm{SD})$ self-reported prepregnancy BMI was $19.2( \pm 1.8) \mathrm{kg} / \mathrm{m}^{2}$, increasing to 22.2 $( \pm 2.2) \mathrm{kg} / \mathrm{m}^{2}$ by 26 to 29 weeks of gestation. Approximately one-third of the women $(32.7 \%)$ were underweight, defined as pre-pregnancy $\mathrm{BMI}<18.5 \mathrm{~kg} / \mathrm{m}^{2}$ prior to pregnancy and $4.0 \%$ of them remained underweight at 26 to 29 weeks of gestation. Almost two-thirds of the women did not meet the gestational weight gain recommended by the IOM at the mid-pregnancy interval of 26 to 29 weeks gestation. At this time, $29.2 \%$ of the mothers also had suboptimal nutritional status, as defined by mid-upper arm circumference $<23.0 \mathrm{~cm}$.

\section{Nutrient inadequacy at 26 to 29 weeks of gestation}

At the baseline data collection (26-29 weeks gestation), $95 \%$ of all the pregnant women in this study $(n=226)$ had concurrent inadequacies for more than five nutrients, and approximately one in two (44\%) had inadequacies for more than ten nutrients (Table 1). The fifteen nutrients that were included in this analysis were protein, calcium, iron, zinc, vitamins A, D, E, C, B1, B2, B3, B5, B6, B9, and B12 (Table 1). Mean (SD) energy and nutrient intakes (without prenatal supplements) at 26 to 29 weeks of gestation in all study participants can be found in Table 2. 
Table 1 Baseline characteristics of all mothers $(n=226)^{a}$

\begin{tabular}{|c|c|}
\hline Baseline characteristics & Mean $( \pm \mathrm{SD}) / \mathrm{n}(\%)$ \\
\hline Age (years), mean (SD) & $24.0(2.9)$ \\
\hline \multicolumn{2}{|l|}{ Economic status, $n(\%)$} \\
\hline Low & $72(31.9)$ \\
\hline Medium & $83(36.7)$ \\
\hline High & $71(31.4)$ \\
\hline \multicolumn{2}{|l|}{ Highest education qualification, $n(\%)$} \\
\hline Primary school & $3(1.3)$ \\
\hline Secondary school & $59(26.1)$ \\
\hline High school & $79(35.0)$ \\
\hline College / University & 85 (37.6) \\
\hline Height (cm), mean (SD) & $154(5.0)$ \\
\hline Pre-pregnancy weight (kg), mean (SD) & $45.5(5.1)$ \\
\hline Pre-pregnancy BMI $\left(\mathrm{kg} / \mathrm{m}^{2}\right)$, mean (SD) & $19.2(1.8)$ \\
\hline \multicolumn{2}{|l|}{ Pre-pregnancy BMI $\left(\mathrm{kg} / \mathrm{m}^{2}\right), n(\%)$} \\
\hline$<18.5$ & $74(32.7)$ \\
\hline$\geq 18.5$ & $152(67.3)$ \\
\hline $\begin{array}{l}\text { Weight at } 26 \text { to } 29 \text { weeks gestation }(\mathrm{kg}) \text {, } \\
\text { mean (SD) }\end{array}$ & $52.7(5.9)$ \\
\hline $\begin{array}{l}\text { BMl at } 26 \text { to } 29 \text { weeks gestation }\left(\mathrm{kg} / \mathrm{m}^{2}\right) \text {, } \\
\text { mean (SD) }\end{array}$ & $22.2(2.2)$ \\
\hline \multicolumn{2}{|l|}{$\begin{array}{l}\text { BMI at } 26 \text { to } 29 \text { weeks gestation }\left(\mathrm{kg} / \mathrm{m}^{2}\right) \text {, } \\
n(\%)\end{array}$} \\
\hline$<18.5$ & $9(4.0)$ \\
\hline$\geq 18.5$ & $217(96.0)$ \\
\hline $\begin{array}{l}\text { Gestational weight gain at } 26 \text { to } 29 \text { weeks } \\
\text { gestation }(\mathrm{kg}) \text {, mean }(\mathrm{SD})^{\mathrm{b}}\end{array}$ & $7.1(2.7)$ \\
\hline \multicolumn{2}{|l|}{$\begin{array}{l}\text { Met IOM recommended gestational weight } \\
\text { gain at } 26 \text { to } 29 \text { weeks gestation }\left(\mathrm{kg} / \mathrm{m}^{2}\right), n(\%)\end{array}$} \\
\hline Yes & $85(38.5)$ \\
\hline No & $136(61.5)$ \\
\hline $\begin{array}{l}\text { MUAC at } 26 \text { to } 29 \text { weeks gestation }(\mathrm{cm}) \text {, } \\
\text { mean (SD) }\end{array}$ & $24.2(2.2)$ \\
\hline \multicolumn{2}{|l|}{$\begin{array}{l}\text { MUAC at } 26 \text { to } 29 \text { weeks gestation }(\mathrm{cm}) \text {, } \\
n(\%)\end{array}$} \\
\hline$<23.0$ & $66(29.2)$ \\
\hline$\geq 23.0$ & $160(70.8)$ \\
\hline \multicolumn{2}{|l|}{ Nutrient inadequacies, $n(\%)^{c}$} \\
\hline$\leq 5$ nutrients & $12(5.3)$ \\
\hline $6-10$ nutrients & $114(50.4)$ \\
\hline 11-15 nutrients & $100(44.3)$ \\
\hline
\end{tabular}

$B M I$ body mass index, MUAC mid-upper arm circumference

aData are presented as means (standard deviations) or numbers (percentages)

${ }^{\mathrm{b}} \mathrm{Gestational}$ weight gain at $26-29$ weeks is calculated by subtracting prepregnancy weight from measured weight at 26-29 weeks

'Selected nutrients include protein, calcium, iron, zinc, vitamins $A, D, E, C, B 1$, $\mathrm{B} 2, \mathrm{~B} 3, \mathrm{~B} 5, \mathrm{~B} 6, \mathrm{~B} 9$, and $\mathrm{B} 12$

Figure 1 shows the percentage of pregnant women with inadequate nutrient intake at baseline (26 to 29 weeks gestation). Over three-quarters of the pregnant
Table 2 Nutrient intake at 26 to 29 weeks of gestation in all study participants $(n=226)^{a}$

\begin{tabular}{lc}
\hline Variables & Mean (SD) \\
\hline Energy (kcal) & $2065(388)$ \\
Protein (g) & $81.4(17.0)$ \\
Fat (g) & $45.2(16.5)$ \\
Carbohydrate (g) & $333(76.3)$ \\
Calcium (mg) & $592(286)$ \\
Iron (mg) & $14.3(5.4)$ \\
Zinc $(\mathrm{mg})$ & $11.4(2.8)$ \\
Vitamin A (mcg) & $608(629)$ \\
Vitamin D (mcg) & $1.23(2.50)$ \\
Vitamin E (mg) & $2.56(1.83)$ \\
Vitamin C (mg) & $144(89.5)$ \\
Vitamin B1 (mg) & $1.43(0.49)$ \\
Vitamin B2 (mg) & $0.95(0.39)$ \\
Vitamin B3 (mg) & $14.9(5.7)$ \\
Vitamin B5 (mg) & $6.56(1.81)$ \\
Vitamin B6 (mg) & $1.43(0.39)$ \\
Vitamin B9 (mcg) & $269(162)$ \\
Vitamin B12 (mcg) & $2.28(3.05)$ \\
\hline a Data a presed as meas (stan & \\
&
\end{tabular}

${ }^{\mathrm{a}}$ Data are presented as means (standard deviations)

women did not meet the adequate intakes for energy, fat, carbohydrate, calcium, iron, zinc, vitamins A, D, E, $\mathrm{B} 2$, and folate at baseline.

There was a significant inverse relationship between the number of nutrient inadequacies $(\leq 5,6-10,11-15)$ and gestational weight gain at 26 to 29 weeks (overall $p=$ 0.045; data not shown). Pairwise comparisons showed that mothers who had 6-10 nutrient inadequacies had lower gestational weight gain at 26 to 29 weeks than did those with $\leq 5$ nutrient inadequacies (mean difference $=-1.05$ $\mathrm{kg}, 95 \%$ CI: $-2.63,0.53 ; p=0.192$ ), although this difference did not reach statistical significance. Mothers who had 11-15 nutrient inadequacies had significantly lower gestational weight gain at 26 to 29 weeks than mothers who had $\leq 5$ nutrient inadequacies (mean difference = $1.71 \mathrm{~kg}, 95 \%$ CI: $-0.11,-3.30 ; p=0.036$ ). Gestational weight gain was positively correlated with the intakes of energy, carbohydrate, protein, calcium, iron, vitamin $\mathrm{C}$, vitamin $\mathrm{B} 2$, vitamin $\mathrm{B} 5$, and vitamin $\mathrm{B} 6$ (all $p \leq 0.030$ ) in univariate analyses (data not shown).

\section{Birth outcomes by study groups}

The mean (SD) gestational age at birth for control and intervention group was $39.1( \pm 1.6)$ weeks and $39.1( \pm 1.3)$ weeks, respectively, infant's birth weight was 3044 ( \pm $385) \mathrm{g}$ and $3153( \pm 347) \mathrm{g}$, respectively, birth length was $48.7(2.25) \mathrm{cm}$ and $49.0( \pm 1.7) \mathrm{cm}$, respectively, and birth head circumference was $32.8( \pm 1.64) \mathrm{cm}$ and $33.1( \pm 1.3)$ 


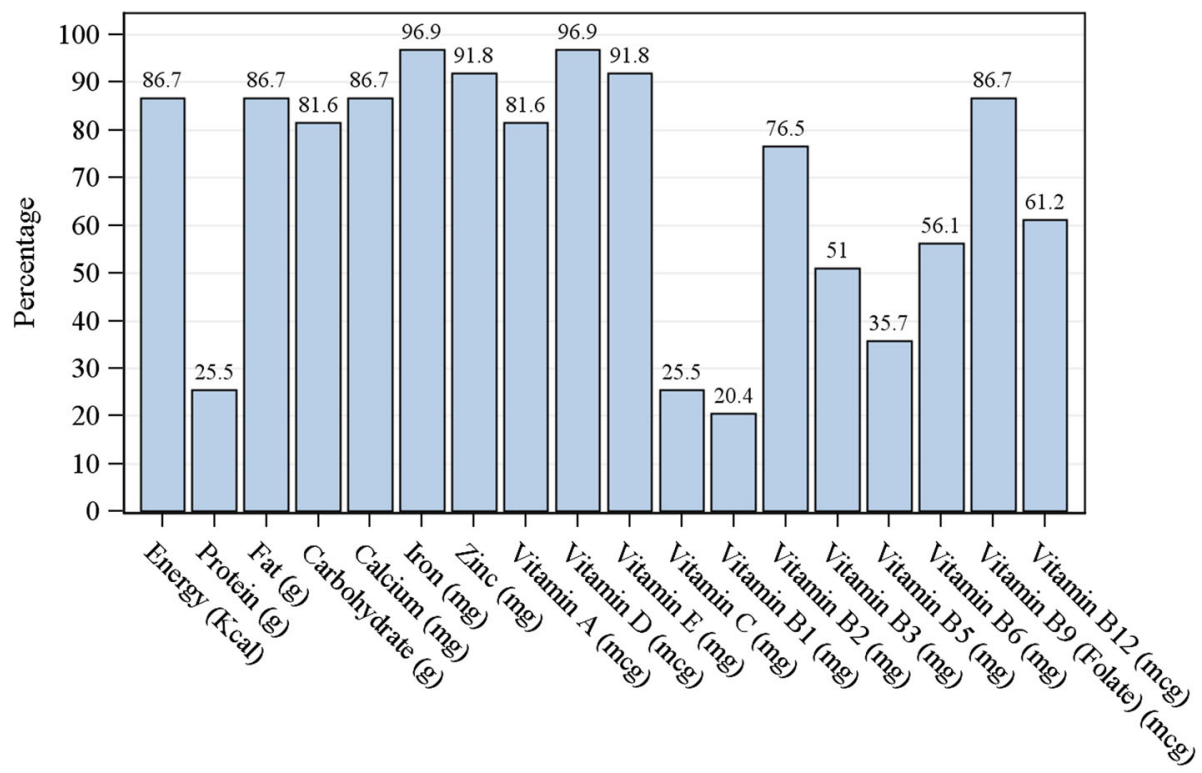

Nutrient

Fig. 1 Percentage of pregnant women with inadequate intake $(<77 \%$ RDA) for selected nutrients at 26 to 29 weeks gestation in all participants $(n=226)$

$\mathrm{cm}$, respectively (Table 3). The infants in the intervention group had significantly higher birth weight than did those in the control group $(p=0.0346)$. There were no significant differences in birth length and birth head circumference between the two groups.

Factors associated with birth outcomes in the control group Table 4 shows the factors that are associated with birth weight, length, and head circumference, as well as birth weight-for-age $z$-score, length-for-age $z$-score, and head circumference-for-age $z$-score in the control group only from the multiple linear analysis $(n=110)$. After adjusting for mother's age at enrollment, gestational age at birth, and infant's gender, gestational weight gain at 26 to 29 weeks was strongly associated with birth weight (adjusted

Table 3 Birth outcomes by study group

\begin{tabular}{lccc}
\hline Characteristics & $\begin{array}{c}\text { Intervention } \\
N=113\end{array}$ & $\begin{array}{c}\text { Control } \\
N=113\end{array}$ & $p$-value \\
\hline Gestational age, mean (SD) & $39.1(1.3)$ & $39.1(1.6)$ & $0.8026^{a}$ \\
$\begin{array}{l}\text { Delivery method, } n(\%) \\
\quad \text { Caesarean }\end{array}$ & $35(31.5)$ & $30(27.3)$ & 0.4872 \\
Infant's sex, n (\%) & & $0.9503^{b}$ \\
$\quad$ Male & $60(54.1)$ & $59(53.6)$ & \\
$\quad$ Female & $51(46.0)$ & $51(46.4)$ & \\
Birth weight (g), mean (SD) & $3153(347)$ & $3044(385)$ & $0.0346^{a}$ \\
Birth length (cm), mean (SD) & $49.0(1.7)$ & $48.7(2.2)$ & $0.5195^{a}$ \\
Head circumference (cm), mean (SD) & $33.1(1.3)$ & $32.7(1.6)$ & $0.1204^{a}$ \\
\hline
\end{tabular}

${ }^{a} p$-value is from Wilcoxon test, ${ }^{b} p$-value is from T-test estimate $=42.9$ g; 95\% CI: 17.5, 68.3), birth length (adjusted estimate $=0.23 \mathrm{~cm} ; 95 \%$ CI: 0.07, 0.39), birth weight-for-age $z$-score (adjusted estimate $=0.10 ; 95 \%$ CI: 0.04, 0.15), and birth length-for-age $z$-score (adjusted estimate $=0.12 ; 95 \%$ CI: 0.04, 0.21) (all $p \leq 0.006$ ). Similarly, education level was positively associated with birth weight $(p=0.029)$, head circumference $(p=0.046)$, birth weight-for-age $z$-score $(p=$ $0.008)$, and a tendency was found for birth length ( $p=$ $0.072)$, birth length-for-age $z$-score $(p=0.076)$, and birth head circumference-for-age $z$-score $(p=0.061)$.

\section{Comparison of birth outcomes between study groups}

We also included some previously published results comparing the birth outcomes between the control and the intervention groups from the original randomized controlled trial for easy reference; that trial evaluated the effects of an improved perinatal nutrition care regimen on birth outcomes [38]. Birth outcomes were compared between study groups using analysis of covariance (ANCOVA) to control for confounding factors, including treatment group, mother's age, mother's nutritional status at baseline, socioeconomic status, gestational age and infant's gender. The infants in the intervention had significantly higher birth weight $(p=0.0312)$, birth weight-for-age $\mathrm{z}$-score $(p=0.0141)$, and head circumference-for-age $\mathrm{z}$ score $(p=0.0487)$, compared with the control (Table 5).

\section{Discussion}

In this study, we examined the nutritional status of pregnant women in Vietnam, particularly the association of 
Table 4 Factors associated with birth outcomes in the control group $(n=110)^{a}$

\begin{tabular}{lcc}
\hline & $\begin{array}{c}\text { Adjusted Estimate } \\
(95 \% \mathrm{Cl})\end{array}$ & $P$ value \\
\hline Birth weight & $-3.9(-24.5,16.7)$ & 0.706 \\
Mother's age at enrollment & $97.4(58.4,136)$ & $<0.001$ \\
$\begin{array}{l}\text { Gestational age at birth } \\
\text { Infant's gender }\end{array}$ & 0.329 \\
$\quad$ Female (reference group) & 0 & \\
$\quad$ Male & $60.4(-61.7,183)$ & \\
$\begin{array}{l}\text { Education level } \\
\text { Primary school (reference } \\
\text { group) }\end{array}$ & 0 & 0.029
\end{tabular}

Secondary school

$687(212,1163)$

High school

College / University

$729(253,1206)$

$739(248,1229)$

Economic status

Low (reference group)

Medium

High

Energy intake at baseline

Energy adjusted carbohydrate intake

Gestational weight gain at 26 to 29 weeks

Birth length

Mother's age at enrollment

Gestational age at birth

Infant's gender

Female (reference group)

Male

Education level

Primary school (reference group)

Secondary school

High school

College / University

Gestational weight gain at 26 to 29 weeks

Birth head circumference

Mother's age at enrollment

Gestational age at birth

Infant's gender

Female (reference group)

Male

Education leve

Primary school (reference group)

Secondary school

$0.04(-0.14,0.22) \quad 0.649$

$0.47(-1.16,2.09)$

0.569

$42.9(17.5,68.3)$

0.001

0

$3.41(0.41,6.41)$

$3.77(0.78,6.77)$

$3.17(0.15,6.19)$

$0.23(0.07,0.39)$

0.006$$
0.15(-0.43,0.72)
$$

0.046
Table 4 Factors associated with birth outcomes in the control group $(n=110)^{a}$ (Continued)

\begin{tabular}{lcc}
\hline & $\begin{array}{c}\text { Adjusted Estimate } \\
(95 \% \mathrm{Cl})\end{array}$ & $P$ value \\
\hline High school & $3.16(0.92,5.39)$ & \\
College / University & $2.93(0.65,5.21)$ & \\
Economic status & 0 & 0.711 \\
Low (reference group) & $-0.14(-0.87,0.59)$ & \\
Medium & $0.20(-0.70,1.10)$ & \\
High & $0.07(-0.06,0.19)$ & 0.292 \\
Gestational weight gain at & & \\
26 to 29 weeks & & 0.592 \\
Birth weight-for-age z-score & $-0.01(-0.06,0.03)$ & $<0.001$ \\
Mother's age at enrollment & $0.22(0.13,0.30)$ & 0.502 \\
Gestational age at birth & $0.09(-0.36,0.18)$ & \\
Infant's gender & 0 & \\
Female (reference group) & 0 &
\end{tabular}

Education level

Primary school (reference group)

Secondary school

High school

College / University

Economic status

Low (reference group)

Medium

High

Energy intake at baseline

$0.0001(-0.0003,0.0005) \quad 0.619$

Energy adjusted fat intake

Gestational weight gain at 26 to 29 weeks

Birth length-for-age $z$-score

Mother's age at enrollment

Gestational age at birth

Infant's gender

Female (reference group)

Male

$-0.005(-0.015,0.005)$

Education level

$$
\begin{array}{ccl}
0.002(-0.10,0.10) & 0.958 & \text { Primary school (reference } \\
0.34(0.15,0.54) & <0.001 & \text { group) } \\
& 0.611 & \text { Secondary school } \\
0 & & \text { High school } \\
\text { College / University }
\end{array}
$$

Gestational weight gain at 26 to 29 weeks

Birth head circumference-forage $z$-score

Mother's age at enrollment
0.008

0.999

$0.0001(-0.34,0.34)$

$0.01(-0.42,0.44)$

0.344

$0.10(0.04,0.15)$

0.001

$0.02(-0.05,0.09)$

0.541

$0.27(0.13,0.40)$

$<0.001$

0.024

0

$-0.48(-0.89,-0.06)$

\section{1}

292

$1.91(0.82,3.01)$

(1)

619
.344
.001
541
0.001
0.024

0.076

0

$1.79(0.19,3.39)$

$1.99(0.39,3.58)$

$1.67(0.06,3.27)$

$0.12(0.04,0.21) \quad 0.006$

$0.002(-0.08,0.08)$ 
Table 4 Factors associated with birth outcomes in the control group $(n=110)^{\mathrm{a}}$ (Continued)

\begin{tabular}{lcc}
\hline & $\begin{array}{c}\text { Adjusted Estimate } \\
(95 \% \mathrm{Cl})\end{array}$ & $P$ value \\
\hline Gestational age at birth & $0.28(0.13,0.44)$ & $<0.001$ \\
Infant's gender & 0 & 0.251 \\
Female (reference group) & $-0.28(-0.74,0.20)$ & \\
Male & & 0.061 \\
Education level & 0 & \\
Primary school (reference group) & $2.12(0.29,3.95)$ & \\
Secondary school & $2.45(0.64,4.27)$ & \\
High school & $2.28(0.43,4.14)$ & \\
College / University & & \\
Economic status & 0.741 \\
Low (reference group) & $0.10(-0.69,0.50)$ & \\
Medium & $0.16(-0.57,0.89)$ & \\
High & $0.05(-0.05,0.15)$ & 0.288 \\
Gestational weight gain at 26 to & & \\
29 weeks
\end{tabular}

${ }^{a}$ Results were derived from multiple linear regression models. Variables with $P<0.20$ in the bivariate analysis as well as mother's age, gestational age at birth, and infant's sex were included in the multiple linear regression models

maternal nutrition status variables with birth outcomes. Our findings showed striking results-one in three women was underweight prior to pregnancy, and one in two pregnant women had concurrent inadequacies for more than ten nutrients at 26 to 29 weeks of gestation. Results also indicated that approximately two-thirds of the pregnant women did not meet the recommended gestational weight gain, as advised by the IOM. There was a proportional relationship between nutrient inadequacies and gestational weight gain, i.e., a higher number of nutrient inadequacies was associated with lower gestational weight gain at 26 to 29 weeks. Gestational weight gain at 26 to 29 weeks was strongly positively associated with birth weight and length in the control group after adjusting for potential confounders.
Our study findings are consistent with previous studies, which reported a prevalence of underweight ranging from 20 to $40 \%$ among women of reproductive age in Asian countries such as China [23], Japan [27] and Vietnam [24, $25,29,47-50]$. Two recent meta-analyses reported that maternal underweight was significantly associated with increased risks for preterm birth by 13 to $30 \%$, having an infant with low birth weight by 66 to $67 \%$, and small for gestational age by 67 to $85 \%$ [41, 51]. Similar findings had been reported in several other reviews, and these findings could be in part due to fetal growth restriction as a result of nutrient inadequacies [29, 30, 32, 52, 53].

We are concerned that a large proportion of pregnant women in the present study did not have adequate intakes for a number of key nutrients that are critical to maternal and infant health-calcium, iron, zinc, vitamins A, Bs, D, and $\mathrm{E}$. These observations are consistent with previous studies reporting high prevalence of micronutrient deficiencies $[47,48,54]$ and insufficient intakes of iron, zinc, folate, vitamin B12, and vitamin A [48, 55] among women of reproductive age or those who are pregnant in Vietnam, particularly among those living in suburban or with lower socio-economic status. When the results are taken together, it appears that the diet for the majority of Vietnamese women falls short of many essential nutrients and multiple nutrient inadequacies often coexist. This observation highlights the importance of improving the intake of a significant number of nutrients in this population group, in addition to the routine iron and folic acid supplementation as part of the standard care. Nutrient requirements increase significantly during pregnancy to support fetal growth and development. Inadequate nutrient intakes during this time may lead to reprogramming within fetal tissues, which could potentially increase the infant's risk of non-communicable chronic diseases in adulthood [5, 17-20]. Recent evidence has shown that dietary interventions during pregnancy significantly improved birth outcomes, especially among women who were malnourished during pregnancy or who had a suboptimal diet $[1,2,12,15,16,56,57]$.

Table $\mathbf{5}$ Comparison of birth outcomes between study groups

\begin{tabular}{|c|c|c|c|}
\hline \multirow[t]{2}{*}{ Growth parameters } & \multicolumn{2}{|l|}{ Estimate $(95 \% \mathrm{Cl})$} & \multirow[t]{2}{*}{$p$-value } \\
\hline & Intervention $(n=104)$ & Control $(n=100)$ & \\
\hline Birth weight (g) & $92(8176)$ & Reference & $0.0312^{\mathrm{a}}$ \\
\hline Birth length $(\mathrm{cm})$ & $0.1(-0.3,0.6)$ & Reference & $0.5452^{a}$ \\
\hline Birth head circumference $(\mathrm{cm})$ & $0.3(0.0,0.6)$ & Reference & $0.0886^{\mathrm{a}}$ \\
\hline Birth weight-for-age z-score & $0.25(0.05,0.45)$ & Reference & $0.0141^{\mathrm{b}}$ \\
\hline Birth length-for-age z-score & $0.18(-0.10,0.46)$ & Reference & $0.2116^{\mathrm{b}}$ \\
\hline Birth head circumference-for-age z-score & $0.31(0.00,0.62)$ & Reference & $0.0487^{b}$ \\
\hline
\end{tabular}

${ }^{a} p$-value is from ANCOVA analysis controlling for treatment group, gestational age and infant sex

${ }^{\mathrm{b}} p$-value from ANCOVA analysis controlling for treatment group, mother's age, mother's nutritional status at baseline, socioeconomic status, gestational age and infant's sex 
Suboptimal weight gain during pregnancy and low birth weight can have long-lasting effects on the child. The present study results reinforce the positive association between gestational weight gain at 26 to 29 weeks and infant's birth weight and length. Numerous studies have consistently demonstrated the efficacy of dietary interventions during pregnancy in lowering the incidence of preterm birth, low birth weight, and small for gestational age and this effect appears to be more pronounced among women who are undernourished during pregnancy [1, 2, 4, 36, 57]. In addition, factors such as poor maternal nutritional status before and during pregnancy, infant's low birth weight and small for gestational age, have been suggested to adversely affect the growth and cognitive development of the offspring $[3,58,59]$, and any increase in birth weight within the normal range has the potential to improve these outcomes after adjusting potential confounders. Therefore, the provision of energy, macronutrient, and micronutrient intakes such as maternal nutritional supplementation to the mothers who have inadequate gestational weight gain during the first and second trimesters could be an effective way to meet nutrient needs and to optimize birth outcomes [1, $15,30,34,53,57]$. Indeed, the present study showed that maternal nutritional supplementation in conjunction with breastfeeding support significantly improved infant's birth weight, weight-for-age $z$-score, and head circumference-for-age $z$-score compared to the control group (all $P \leq 0.049$ ) [38].

The strength of the current study is that it includes the measure and reports on a comprehensive range of demographic, anthropometric, and dietary variables, which advances our understanding of the effects of these variables on birth outcomes. Previous research findings showed an association between maternal nutritional status and birth outcomes, albeit the outcome was mainly on birth weight. The current study extends knowledge in this area by determining the relationship of various maternal nutritional indices with birth length and birth head circumference in addition to birth weight. Gestational weight gain at 26 to 29 weeks was positively associated with infant's birth weight and birth weight-for-age z-score as well as birth length and birth length-for-age z-score. This finding suggests that low birth length could be a sensitive birth outcome parameter that is associated with inadequate gestational weight gain in a population group with high prevalence of suboptimal maternal nutritional status. Further research is warranted to confirm this finding.

This study has limitations. First, we did not measure the mother's weight at delivery, hence the full gestational weight gain could not be determined. Previous studies examining the association between total gestational weight gain and birth outcomes reported similar findings [21, 23, $27,28]$, and a recent study reported that maternal weight gain during early pregnancy ( $\leq 20$ weeks) and mid pregnancy (21-29 weeks) had a stronger influence on fetal growth and birth outcomes compared to weight gain in later pregnancy ( $\geq 30$ weeks) [24]. Second, using recall pre-pregnancy weight for calculating pre-pregnancy BMI may be subject to recall biases. Third, we used the earliest weight measure in the first trimester as a proxy for prepregnancy weight in those subjects (5.2\%) who could not recall pre-pregnancy weight. This may underestimate the prevalence of underweight in pregnant women. Finally, the current study was the secondary analysis utilizing the baseline data from a randomized controlled trial that was designed to evaluate the impact of an improved perinatal nutrition care program on breastfeeding, birth and growth outcomes. Hence, the sample size was relatively small, which may limit the generalizability of the results. Future research with larger sample size and wider population groups is warranted to elucidate the underlying mechanisms and the potential roles for maternal nutrition care in optimizing pregnancy outcomes.

\section{Conclusions}

Findings from our study showed that nutrient inadequacies during pregnancy are prevalent among Vietnamese women, often occurring as concurrent inadequacies of multiple nutrients. Maternal underweight prior to pregnancy and women not meeting recommended gestational weight gain were also frequent in our Vietnamese study population.

Our results underscore the need for building policies and implementing public health initiatives aimed to improve dietary quality among girls and women of reproductive age. In particular, prenatal nutrition care must promote optimal gestational weight gain among pregnant women. Such steps are necessary to improve both short- and long-term health outcomes for mothers and their children.

\section{Abbreviations}

BMI: Body mass index; Cl: Confidence interval; IOM: Institute of Medicine; WHO: World Health Organization

\begin{abstract}
Acknowledgements
We thank all the women and infants for their commitment in taking part in this study. We also thank the study team of Abbott Nutrition and the study team of the National Institution of Nutrition, Ha Nam, Hai Phong, Ninh Binh, and Thai Nguyen Provinces for their assistance during the study.
\end{abstract}

\section{Authors' contributions}

DTTH and YLL designed the study. TTN and NTL reviewed and provided inputs on the study design and methodology. TTN and NTL were responsible for subject recruitment and data collection. SLT, DTTH, TTN, NTL, YB and LYL contributed in data analysis and interpretation. SLT and DTTH drafted the manuscript. All authors critically reviewed the manuscript and approved the final version submitted for publication. 


\section{Funding}

This study was funded and supported by Abbott Nutrition. Abbott Nutrition was involved in the study design, data collection and analysis, and preparation of the manuscript.

\section{Availability of data and materials}

The data that support the findings of this study are available from Abbott Nutrition, but restrictions apply to the availability of these data, which were used under license for the current study, and so are not publicly available. Data are however available from the authors upon reasonable request and with permission of Abbott Nutrition

\section{Ethics approval and consent to participate}

The study was approved by the Independent Ethics Committees of the National Institution of Nutrition and the Ministry of Health in Vietnam. Informed written consent was obtained from each mother at baseline. The infant's parents signed and dated the informed consent form within $48 \mathrm{~h}$ of delivery for the infant's participation in the study. The study was performed in accordance with the ethical principles that had their origin in the Declaration of Helsinki.

\section{Consent for publication}

Not applicable.

\section{Competing interests}

SLT, YLL and DTTH are employees of Abbott Nutrition. YB is an employee of Cognizant Technologies Solution Pvt. Ltd., a Contract Research Organization providing statistical services to Abbott Nutrition.

\section{Author details}

${ }^{1}$ Micronutrient Research and Application, National Institution of Nutrition, 48B Tang Ba Ho, Hai Ba Trung District, Ha Noi, Vietnam. ${ }^{2}$ Clinical Nutrition, National Institution of Nutrition, 48B Tang Ba Ho, Hai Ba Trung District, Ha Noi, Vietnam. ${ }^{3}$ Statistical Services, Cognizant Technologies Solution Pvt. Ltd, Hiranandani Business Park, Mumbai 400076, India. ${ }^{4}$ Abbott Nutrition Research and Development Asia-Pacific Center, 20 Biopolis Way, Unit 09-01/02 Centros Building, Singapore 138668, Singapore.

\section{Received: 13 May 2018 Accepted: 27 November 2019}

\section{Published online: 04 December 2019}

\section{References}

1. Gresham E, Byles JE, Bisquera A, Hure AJ. Effects of dietary interventions on neonatal and infant outcomes: a systematic review and meta-analysis. Am J Clin Nutr. 2014;100(5):1298-321.

2. Gresham E, Bisquera A, Byles JE, Hure AJ. Effects of dietary interventions on pregnancy outcomes: a systematic review and meta-analysis. Matern Child Nutr. 2016;12(1):5-23.

3. Nnam NM. Improving maternal nutrition for better pregnancy outcomes. Proc Nutr Soc. 2015;74(4):454-9.

4. Papathakis PC, Singh LN, Manary MJ. How maternal malnutrition affects linear growth and development in the offspring. Mol Cell Endocrinol. 2016:435:40-7.

5. Procter SB, Campbell CG. Position of the academy of nutrition and dietetics: nutrition and lifestyle for a healthy pregnancy outcome. J Acad Nutr Diet. 2014;114(7):1099-103.

6. Bukhary NBI, Isa ZM, Shamsuddin K, Lin KG, Mahdy ZA, Hassan H, Yeop NSH. Risk factors for antenatal hypovitaminosis $d$ in an urban district in Malaysia. BMC Pregnancy Childbirth. 2016:16(1):156

7. Ministry of Health and Sports (MoHS) and ICF. Myanmar demographic and health survey 2015-16. Pyi Taw and Rockville: Ministry of Health and Sports and ICF; 2017

8. Moench-Pfanner R, Silo S, Laillou A, Wieringa F, Hong R, Hong R, Poirot E, Bagriansky J. The economic burden of malnutrition in pregnant women and children under 5 years of age in Cambodia. Nutrients. 2016;8(5):292.

9. Sukchan $P$, Liabsuetrakul $T$, Chongsuvivatwong $V$, Songwathana $P$, Sornsrivichai $V$, Kuning M. Inadequacy of nutrients intake among pregnant women in the deep south of Thailand. BMC Public Health. 2010;10(1):572.

10. The Food and Nutrition Research Institute of the Department of Science and Technology (FNRIDOST). 8th national nutrition survey 2013. Philippines: Food and Nutrition Research Institute; 2017.
11. Winichagoon P. Thailand nutrition in transition: situation and challenges of maternal and child nutrition. Asia Pac J Clin Nutr. 2013;22(1):6-15.

12. Grieger J, Clifton V. A review of the impact of dietary intakes in human pregnancy on infant birthweight. Nutrients. 2015;7(1):153-78.

13. Haider BA, Bhutta ZA. Multiple-micronutrient supplementation for women during pregnancy. Cochrane Database Syst Rev. 2017;(4):Art. No.: CD004905. https://doi.org/10.1002/14651858.CD004905.pub5.

14. Martin JC, Zhou SJ, Flynn AC, Malek L, Greco R, Moran L. The assessment of diet quality and its effects on health outcomes pre-pregnancy and during pregnancy. Semin Reprod Med. 2016;34(02):83-92.

15. Vaivada T, Gaffey MF, Das JK, Bhutta ZA. Evidence-based interventions for improvement of maternal and child nutrition in low-income settings: What's new? Curr Opin Clin Nutr Metab Care. 2017:20(3):204-10.

16. Victora CG, de Onis M, Hallal PC, Blössner M, Shrimpton R. Worldwide timing of growth faltering: revisiting implications for interventions. Pediatrics. 2010;125(3):e473-80

17. Canani RB, Di Costanzo M, Leone L, Bedogni G, Brambilla P, Cianfarani S, Nobili V, Pietrobelli A, Agostoni C. Epigenetic mechanisms elicited by nutrition in early life. Nutr Res Rev. 2011;24(2):198-205.

18. Danielewicz H, Myszczyszyn G, Dębińska A, Myszkal A, Boznański A, Hirnle L. Diet in pregnancy - more than food. Eur J Pediatr. 2017;176(12):1573-9.

19. Hanley B, Dijane J, Fewtrell M, Grynberg A, Hummel S, Junien C, Koletzko B, Lewis S, Renz H, Symonds M, et al. Metabolic imprinting, programming and epigenetics - a review of present priorities and future opportunities. $\mathrm{Br} J$ Nutr. 2010;104(S1):S1-S25.

20. Lowensohn RI, Stadler DD, Naze C. Current concepts of maternal nutrition. Obstet Gynecol Surv. 2016;71(7):413-26.

21. Enomoto K, Aoki S, Toma R, Fujiwara K, Sakamaki K, Hirahara F. Pregnancy outcomes based on pre-pregnancy body mass index in japanese women. PLoS One. 2016;11(6):e0157081.

22. Pongcharoen $T$, Gowachirapant $S$, Wecharak $P$, Sangket $N$, Winichagoon $P$ Pre-pregnancy body mass index and gestational weight gain in thai pregnant women as risks for low birth weight and macrosomia. Asia Pac J Clin Nutr. 2016;25(4):810-7.

23. Xiao L, Ding G, Vinturache A, Xu J, Ding Y, Guo J, Huang L, Yin X, Qiao J, Thureraja I, et al. Associations of maternal pre-pregnancy body mass index and gestational weight gain with birth outcomes in shanghai, China. Sci Rep. 2017:7:41073.

24. Young MF, Hong Nguyen $P$, Addo OY, Pham H, Nguyen S, Martorell R, Ramakrishnan U. Timing of gestational weight gain on fetal growth and infant size at birth in Vietnam. PLoS One. 2017;12(1):e0170192.

25. Hanieh S, Ha TT, Simpson JA, Thuy TT, Khuong NC, Thoang DD, Tran TD, Tuan T, Fisher J, Biggs B-A. Postnatal growth outcomes and influence of maternal gestational weight gain: a prospective cohort study in rural Vietnam. BMC Pregnancy Childbirth. 2014;14(1):339.

26. Goldstein RF, Abell SK, Ranasinha S, et al. Association of gestational weight gain with maternal and infant outcomes: a systematic review and metaanalysis. JAMA. 2017;317(21):2207-25

27. Murai U, Nomura K, Kido M, Takeuchi T, Sugimoto M, Rahman M. Prepregnancy body mass index as a predictor of low birth weight infants in Japan. Asia Pac J Clin Nutr. 2017;26(3):434-7.

28. Nomura K, Kido M, Tanabe A, Nagashima K, Takenoshita S, Ando K. Investigation of optimal weight gain during pregnancy for japanese women. Sci Rep. 2017;7(1):2569.

29. Ota E, Haruna M, Suzuki M, Anh DD, Tho LH, Tam NTT, Thiem VD, Anh NTH, Isozaki M, Shibuya K, et al. Maternal body mass index and gestational weight gain and their association with perinatal outcomes in Viet Nam. Bull World Health Organ. 2011;89(2):127-36

30. Wrottesley SV, Lamper C, Pisa PT. Review of the importance of nutrition during the first 1000 days: maternal nutritional status and its associations with fetal growth and birth, neonatal and infant outcomes among african women. J Dev Orig Health Dis. 2016;7(2):144-62.

31. Berti C, Cetin I, Agostoni C, Desoye G, Devlieger R, Emmett PM, Ensenauer R,

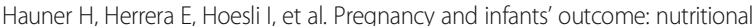
and metabolic implications. Crit Rev Food Sci Nutr. 2016;56(1):82-91.

32. Black RE, Victora CG, Walker SP, Bhutta ZA, Christian $P$, de Onis M, Ezzati M, Grantham-McGregor S, Katz J, Martorell R, et al. Maternal and child undernutrition and overweight in low-income and middle-income countries. Lancet. 2013;382(9890):427-51.

33. Kominiarek MA, Peaceman AM. Gestational weight gain. Am J Obstet Gynecol. 2017;217(6):642-51. 
34. Ahmed T, Hossain M, Sanin Kl. Global burden of maternal and child undernutrition and micronutrient deficiencies. Ann Nutr Metab. 2012; 61(Suppl. 1):8-17.

35. Christian P, Mullany LC, Hurley KM, Katz J, Black RE. Nutrition and maternal, neonatal, and child health. Semin Perinatol. 2015;39(5):361-72.

36. Stevens B, Buettner P, Watt $K$, Clough A, Brimblecombe J, Judd J. The effect of balanced protein energy supplementation in undernourished pregnant women and child physical growth in low- and middle-income countries: a systematic review and meta-analysis. Matern Child Nutr. 2015;11(4):415-32

37. Yan J. Maternal pre-pregnancy bmi, gestational weight gain, and infant birth weight: a within-family analysis in the United States. Econ Hum Biol. 2015;18:1-12.

38. Huynh DTT, Tran NT, Nguyen LT, Berde Y, Low YL. Impact of maternal nutritional supplementation in conjunction with a breastfeeding support program on breastfeeding performance, birth, and growth outcomes in a vietnamese population. J Matern Fetal Neonatal Med. 2017;31:1-9.

39. Filmer D, Pritchett LH. Estimating wealth effects without expenditure data_or tears: an application to educational enrollments in states of India. Demography. 2001;38(1):115-32.

40. Institute of Medicine (IOM) and National Research Council (NRC). Weight gain during pregnancy: Reexamining the guidelines. Washington, DC: The National Academies Press; 2009.

41. Rahman MM, Abe SK, Kanda M, Narita S, Rahman MS, Bilano V, Ota E, Gilmour S, Shibuya K. Maternal body mass index and risk of birth and maternal health outcomes in low- and middle-income countries: a systematic review and meta-analysis. Obes Rev. 2015;16(9):758-70.

42. Ververs M-T, Antierens A, Sackl A, Staderini N, Captier V. Which anthropometric indicators identify a pregnant woman as acutely malnourished and predict adverse birth outcomes in the humanitarian context? PLoS Curr. 2013;5 ecurrents.dis.54a58b618c611bc031ea140e613f2934599c2934598.

43. Vietnam National Institute of Nutrition. Vietnam recommended dietary allowances 2016. Hanoi: Medical Publishing House; 2016.

44. Gibson RS. Evaluation of nutrient intakes and diets. In: Gibson RS, editor. Principles of nutritional assessment. New York: Oxford University Press; 2005. p. 197-228

45. Who Multicentre Growth Reference Study Group. Who child growth standards based on length/height, weight and age. Acta Paediatr. 2006;95: 76-85.

46. Lee PA, Chernausek SD, Hokken-Koelega ACS, Czernichow P. International small for gestational age advisory board consensus development conference statement: management of short children born small for gestational age, april 24-october 1, 2001. Pediatrics. 2003;111(6):1253-61.

47. Laillou A, Pham TV, Tran NT, Le HT, Wieringa F, Rohner F, Fortin S, Le MB, Tran DT, Moench-Pfanner R, et al. Micronutrient deficits are still public health issues among women and young children in Vietnam. PLoS One. 2012;7(4):e34906.

48. Tu N, King JC, Dirren H, Thu HN, Ngoc QP, Diep ANT. Effect of animalsource food supplement prior to and during pregnancy on birthweight and prematurity in rural Vietnam: a brief study description. Food Nutr Bull. 2014; 35(4 Suppl):S205-8.

49. Vietnam Ministry of Health. In: National Institute of Nutrition, editor. General nutrition survey 2009-2010. Ha Noi: Ministry of Health; 2012.

50. Young MF, Nguyen PH, Addo OY, Hao W, Nguyen H, Pham H, Martorell R, Ramakrishnan $U$. The relative influence of maternal nutritional status before and during pregnancy on birth outcomes in Vietnam. Eur J Obstet Gynecol Reprod Biol. 2015;194:223-7.

51. Liu P, Xu L, Wang Y, Zhang Y, Du Y, Sun Y, Wang Z. Association between perinatal outcomes and maternal pre-pregnancy body mass index. Obes Rev. 2016;17(11):1091-102.

52. Pan Y, Zhang S, Wang Q, Shen H, Zhang Y, Li Y, Yan D, Sun L. Investigating the association between prepregnancy body mass index and adverse pregnancy outcomes: A large cohort study of 536098 chinese pregnant women in rural china. BMJ Open. 2016;6(7):1-8.

53. Ramakrishnan U, Grant F, Goldenberg T, Zongrone A, Martorell R. Effect of women's nutrition before and during early pregnancy on maternal and infant outcomes: a systematic review. Paediatr Perinat Epidemiol. 2012;26:285-301.

54. Khan NC, Hoan PV. Vietnam recommended dietary allowances 2007. Asia Pac J Clin Nutr. 2008;17(Suppl 2):409-15.

55. Nguyen PH, Nguyen H, Gonzalez-Casanova I, Copeland E, Strizich G, Lowe A, Pham H, Truong TV, Nguyen S, Martorell R, et al. Micronutrient intakes among women of reproductive age in Vietnam. PLoS One. 2014;9(2):e89504.
56. Dewey KG. Reducing stunting by improving maternal, infant and young child nutrition in regions such as south asia: evidence, challenges and opportunities. Matern Child Nutr. 2016;12(Suppl. 1):27-38.

57. Imdad A, Bhutta ZA. Maternal nutrition and birth outcomes: effect of balanced protein-energy supplementation. Paediatr Perinat Epidemiol. 2012; 26:178-90.

58. Shenkin SD, Starr JM, Deary IJ. Birth weight and cognitive ability in childhood: a systematic review. Psychol Bull. 2004;130(6):989-1013.

59. Veena SR, Gale CR, Krishnaveni GV, Kehoe SH, Srinivasan K, Fall CHD. Association between maternal nutritional status in pregnancy and offspring cognitive function during childhood and adolescence; a systematic review. BMC Pregnancy Childbirth. 2016;16(1):220

\section{Publisher's Note}

Springer Nature remains neutral with regard to jurisdictional claims in published maps and institutional affiliations.
Ready to submit your research? Choose BMC and benefit from:

- fast, convenient online submission

- thorough peer review by experienced researchers in your field

- rapid publication on acceptance

- support for research data, including large and complex data types

- gold Open Access which fosters wider collaboration and increased citations

- maximum visibility for your research: over $100 \mathrm{M}$ website views per year

At $\mathrm{BMC}$, research is always in progress.

Learn more biomedcentral.com/submissions 